AGRICA: Journal of Sustainable Dryland Agriculture, 12 (2): 137-150 (2019)

ISSN-Online : 2715-4955; ISSN-Cetak: 2715-6613

DOI: https://doi.org/10.37478/agr.v12i2.308

\title{
PENGARUH DOSIS PUPUK KANDANG AYAM TERHADAP PERTUMBUHAN DAN PRODUKSI TANAMAN KACANG TANAH (Arachis hypogea L.) DI DESA REROROJA KECAMATAN MAGEPANDA KABUPATEN SIKKA
}

\author{
Yoseph Siga ${ }^{1}$ dan Yovita Yashinta Bolly ${ }^{2}$ \\ Program Studi Agroteknologi, Fakultas Pertanian, Universitas Nusa Nipa ${ }^{1}$ \\ Jl. Kesehatan-Alok Timur, Sikka-Flores, NTT \\ Vytayovieeta@gmail.com
}

\begin{abstract}
The effect of chicken fertilizer dosage on growth and production of land bean (Arachis hypogea l.) in reroroja village, magepanda district, sikka district. Peanut belongs to the Leguminosae family, which has the opportunity to develop agroindustry in supporting efficient and effective regional economic development. The purpose of this study was to determine the effect of giving chicken manure to the growth and production of peanut plants as well as the optimal dose of chicken manure for the growth and production of peanut plants. The study conducted from June 2018 to October 2018. The study used a randomized block design (RBD) with six treatments and four replications so that twenty-four (24) trial units were obtained. Factor A0: No fertilizer (control), A1: $1.5 \mathrm{~kg}, \mathrm{~A} 2: 3 \mathrm{~kg}$, A3: 4,5, A4: 6, A5: $7 \mathrm{Kg}$ per bed. The results showed that the provision of chicken manure significantly affected the height of plants aged 15 and 30 HST. Significantly affect the number of leaves of plants aged 15 and 30 HST. Very significant effect on the number of pods aged 90 Hst and very significant effect on the weight or wet weight of peanut pods aged 90 Hst. The dose of chicken manure 25 tons/ha in this study is the best fertilizer dosage treatment to provide the highest growth and production of Hypoma one peanut.
\end{abstract}

Keywords : chicken manure, peanut, growth and production.

\section{PENDAHULUAN}

Kacang tanah merupakan tanaman komersial sebagai sumber pendapatan penting bagi petani di lahan kering dan lahan sawah. Kacang tanah memiliki peluang pengembangan agroindustri dalam mendukung pembangunan perekonomian daerah yang efisien dan efektif (Sudjadi dan Supriati, 2001).

Kacang tanah termasuk famili Leguminosaceae yang umumnya mempunyai bintil akar yang mampu melakukan fiksasi nitrogen. Kacang tanahdapat dikonsumsi dalam berbagai bentuk, antara lain sebagai sayur, saus, kacang goreng atau kacang rebus, selain itu kacang tanah juga dapat digunakan sebagai bahan industri antara lain untuk bahan mentah keju, mentega, sabun dan minyak. Daun kacang tanah dapat digunakan untuk pakan ternak, sedangkan bungkilnya dapat dijadikan oncom dengan bantuan fermentasi jamur (Marzuki, 2007). 
Siga: Pengaruh dosis pupuk kandang ayam terhadap pertumbuhan dan produksi tanaman kacang panjang

Produksi kacang tanah di Kabupaten Sikka sejak tahun 2015 sampai dengan tahun 2017 mengalami peningkatan sejalan dengan peningkatan luas panen yaitu tahun 2015 luas panen 1.850 ha dengan produksi 1.762 ton, tahun 2016 luas panen 1.902 ha dengan produksi 1.882 ton dan tahun 2017 luas panen 1,908 ha dengan produksi 1.888 ton (Dinas Pertanian Kabupaten Sikka, 2018). Peningkatan produksi kacang tanah tersebut belum signifikan, maka salah satu upaya yang dapat dilakukan untuk meningkatkan produksi kacang tanah yaitu dengan pemberian unsur hara melalui kegiatan pemupukan.

Tanah merupakan faktor penting dalam budidaya tanaman kacang tanah karena fungsinya sebagai penyedia unsur hara. Ketersediaan unsur hara tertentu dipengaruhi oleh jenis tanah. Unsur fosfat (P) adalah unsur esensial kedua setelah nitrogen $(\mathrm{N})$ yang berperan penting dalam fotosintesis dan perkembangan akar. Pada tanah-tanah yang miskin unsur fosfat, kacang tanah akan mempunyaiperakaran yang lemah, tumbuhnya kerdil, daunnya kecil berwarna hijau kecoklatan atau merah, bunga banyak yang gugur busuk atau mati, waktu masak buah terlambat dan polong banyak yang hampa (Huda, 2007).

Pemupukan merupakan alternatif yang dilakukan untuk mendukung upaya peningkatan hasil kacang tanah terutama pada lahan yang kandungan unsur haranya rendah. Pemberian pupuk organik seperti pupuk kandang dalamtanah dapat memperbaiki sifat fisik, kimia dan biologi tanah. Pengaruh terhadap sifat fisik tanah di antaranya adalah dapat meningkatkan daya tahan air, sedangkan Terhadap kimia tanah dapat menambah unsur hara ke dalam tanah dan dapat pula meningkatkan daya tukar kation terhadap sifat biologi tanah adalah sebagai media jasad renik (Musnamar, 2007).

Penambahan bahan organik seperti pupuk kandang ke dalam tanah merupakan salah satu teknik budidaya yang lebih baik dari segi teknis, ekonomis, sosial maupun dari lingkungan karena tidak menimbulkan pencemaran. Pupuk kandang mengandung unsur hara lengkap yang dibutuhkan tanaman.Kotoran ternak atau hewan mengandung berbagai jenis nutrisi yang dibutuhkan oleh tanaman. Nutrisi tersebut terdiri atas dua jenis unsur yaitu (1) unsur hara makro dan (2) unsur hara mikro. Unsur makro berupa Kalsium (Ca), Nitrogen (N), Sulfur (S), Kalium (K), Fosfor (P), dan Magnesium $(\mathrm{Mg})$. Sedangkan unsur mikro terdiri dari Besi (Fe), Tembaga $(\mathrm{Cu})$, Boron (B), Seng ( $\mathrm{Zn})$, Klor ( $\mathrm{Cl}$ ), Molybdenum (M), dan Almunium (Al) (Lingga, 1992).

Pemberian pupuk kandang ayam dapat memberikan pengaruh untuk memperbaiki aerase tanah, menambah kemampuan tanah menyimpan unsur hara, meningkatkan kapasitas menahan air, meningkatkan daya sanggah tanah, sebagai sumber unsur hara dan sumber energi bagi mikroorganisme tanah (Hardjowigeno, 2003 dalam Marlina dkk, 2014).

Pupuk kandang ayam mempunyai potensi yang baik dalam peningkatan pertumbuhan dan produksi tanaman, karena pupuk kandang ayam mempunyai kandungan $\mathrm{N}$, P, dan $\mathrm{K}$ yang lebih tinggi 
bila dibandingkan pupuk kandang lainnya (Roidah, 2013).Kotoran ayam memiliki kandungan unsur hara $\mathrm{N} 1,5 \%$, P 1,3\%, K 0,8\% dan kadar air 57\% (Lingga, 1991).Hasil peneltian (Marlina dkk, 2014) pada perlakuan pupuk kandang ayam dengan ukuran bedeng 1,5 m x 2 myang diaplikasikan pada tanaman kacang tanahmenunjukkan bahwa perlakuan 10 ton/ha merupakan dosis pupuk terbaik untuk meningkatkan pertumbuhan dan produksi kacang tanah yaitusebesar $\quad 2,73 \quad \mathrm{~kg} / \mathrm{bedeng}$. Berdasarkan uraian diatas peneliti merasa perlu untuk melakukan penelitian dengan judul "Pengaruh Pupuk kandang Ayam Terhadap Pertumbuhandan Produksi Tanaman Kacang Tanah (Arachis hypogea L.) Di Desa Reroroja Kecamatan Magepanda Kabupaten Sikka".

\section{METODE PENELITIAN}

\section{Tempat dan Waktu}

Penelitian ini telah dilaksanakan di Desa Reroroja, Kecamatan Magepanda, Kabupaten Sikka pada bulan Junisampai Oktober 2018.

\section{Bahan dan Alat}

Bahan yang diperlukan adalah : Benih kacang tanah varietas Hypoma 1, Pupuk kandang ayam, Air bersih, dan Rhizobium Tanisoy. Sedangkan alat yang digunakan adalah: Mesin bajak, Gembor, Alat tulis menulis, Skop, Timbangan, Meter, Tali raffia, Cangkul dan Alat tugal.

\section{Rancangan Percobaan}

Rancangan percobaan yang digunakan dalam penelitian ini adalah Rancangan Acak Kelompok (RAK). Penelitian ini terdiri atas satu faktor dengan enam kali perlakuan dan empat kali ulangan sehingga diperoleh 24 unit percobaan.

Pemberian pupuk kandang ayam (A) terdiri dari :

$>$ A0 : Tanpa pupuk (kontrol)

$>\mathrm{A} 1: 5$ ton/ha setara dengan $1,5 \mathrm{~kg} /$ bedeng

$>$ A2 : 10 ton/ha setara dengan $3 \mathrm{~kg} / \mathrm{bedeng}$

$>$ A3 : 15 ton/ha setara dengan $4,5 \mathrm{~kg} / \mathrm{bedeng}$

$>$ A4 : 20 ton/ha setara dengan $6 \mathrm{~kg} /$ bedeng A5 : 25 ton/hasetara dengan $7,5 \mathrm{~kg} / \mathrm{bedeng}$

\section{Prosedur Penelitian}

Prosedur penelitian terdiri dari pengolahan lahan, pemupukan, pemilihan benih, penanaman, pemeliharaan dan panen

\section{Variabel Pengamatan}

Variabel yang diamati dalam penelitian ini terdiri variable pertumbuhan dan hasil. Variabel Pertumbuhan terdiri dari tinggi tanaman dan jumlah daun.

Sedangkan variable hasil terdiri dari jumlah polong dan berat basah polong.

\section{Metode Pengumpulan Data Penelitian}

a. Metode Survei Lapangan

Data yang diperoleh secara langsung pada saat penelitian yaitu dengan membuat perlakuan setiap unit percobaan yang diteliti, setiap kejadian dicatat dengan baik. 
Siga: Pengaruh dosis pupuk kandang ayam terhadap pertumbuhan dan produksi tanaman kacang panjang

\section{b. Metode Perpustakaan}

Menelaah diberbagai literatur sesuai dengan topik penelitian.

\section{Analisis Data}

Data yang di peroleh dianalisis dengan menggunakan Rancangan Acak Kelompok (RAK) dan bila uji ANOVA ( Analisis of Variance) berbeda tidak nyata ( $\mathrm{F}$ hitung $<\mathrm{F}$ tabel $5 \%$ ) tidak di lakukan uji lanjutan, sedangkan bila hasil sidik ragam berbeda nyata ( $\mathrm{F}$ hitung $>\mathrm{F}$ tabel $1 \%$ ), maka untuk membandigkan kedua rata-rata perlakuan di lakukan uji lanjutan dengan uji Beda Nyata Terkecil (BNT) taraf 5\% .

\section{HASIL DAN PEMBAHASAN \\ Pengamatan Tinggi Tanaman}

Secara umum hasil pengamatan terhadap Tinggi Tanaman kacang tanah dengan uji ANOVA disajikan pada tabel 4.2.1 dan 4.2.2. Pengamatan tinggi tanaman dilakukan pada saat umur tanaman 15 dan 30 (hst). Pengukuran tinggi tanaman menggunakan mistar, dimulai dari pangkal batang hingga ujung tanaman tertinggi. Laju pertumbuhan tinggi tanaman kacang tanah pada perlakuan dosis pupuk kandang ayam dapat dilihat pada tabel berikut ini.

Tabel 4.2.1 Data Pengamatan Tinggi Tanaman(cm) 15 hst.

\begin{tabular}{|c|c|c|c|c|c|c|c|}
\hline \multirow{2}{*}{ Perlakuan } & \multicolumn{4}{|c|}{ Ulangan } & \multirow{2}{*}{ Total } & \multirow{2}{*}{$\begin{array}{c}\text { Rata- } \\
\text { rata }\end{array}$} & \multirow{2}{*}{$\begin{array}{l}\text { Simbol } \\
\text { Notasi }\end{array}$} \\
\hline & I & II & III & IV & & & \\
\hline A0 & 2,63 & 5,25 & 3,38 & 3,88 & 5,14 & 3,79 & A \\
\hline A1 & 3,38 & 4,25 & 4,63 & 5,38 & 17,64 & 4,41 & B \\
\hline A2 & 4,38 & 5,00 & 3,75 & 5,63 & 18,76 & 4,69 & $\mathrm{D}$ \\
\hline A3 & 4,88 & 4,50 & 4,10 & 5,00 & 18,48 & 4,62 & $\mathrm{C}$ \\
\hline A4 & 4,38 & 5,13 & 4,63 & 5,13 & 19,27 & 4,82 & E \\
\hline A5 & 5,72 & 5,60 & 5,60 & 5,70 & 22,62 & 5,66 & $\mathrm{~F}$ \\
\hline
\end{tabular}

Rerata : 4,66

KK : 12,51

Sumber : data primer diolah,(2018) 
Tabel 4.2.2 Data Pengamatan Tinggi Tanaman (cm) 30 hst.

\begin{tabular}{cccccccc}
\hline \multirow{2}{*}{ Perlakuan } & \multicolumn{4}{c}{ Ulangan } & Total & $\begin{array}{c}\text { Rata- } \\
\text { rata }\end{array}$ & $\begin{array}{c}\text { Simbol } \\
\text { Notasi }\end{array}$ \\
\hline A0 & 11,50 & 10,25 & 7,88 & 11,75 & 41,38 & 10,34 & $\mathrm{a}$ \\
A1 & 10,63 & 11,63 & 11,43 & 12,25 & 45,93 & 11,48 & $\mathrm{~b}$ \\
A2 & 12,13 & 12,00 & 10,50 & 12,25 & 46,88 & 11,72 & $\mathrm{c}$ \\
A3 & 12,25 & 12,25 & 11,75 & 11,88 & 48,13 & 12,03 & $\mathrm{~d}$ \\
A4 & 12,00 & 11,88 & 12,00 & 12,50 & 48,38 & 12,09 & $\mathrm{e}$ \\
A5 & 12,00 & 13,88 & 12,13 & 12,63 & 50,13 & 12,53 & $\mathrm{f}$ \\
\hline
\end{tabular}

Rerata : 11,70

KK : 6,68

Sumber : data primer diolah, (2018)

Dari hasil analisis uji ANOVA menunjukkanperlakuan dosis pupuk kandang ayammemberikan pengaruh yang nyata terhadap tinggi tanaman kacang tanah pada umur tanaman 15 dan 30 (HST). Hal ini terlihat dari nilai $\mathrm{F}$ hitung lebih besar dari $\mathrm{F}$ tabel. Selanjutnya terdapat perbedaan yang nyata antara perlakuan, yaitu terlihat dari hasil uji BNT 5\%, perlakuan $\mathrm{A} 0, \mathrm{~A} 1, \mathrm{~A} 2, \mathrm{~A} 3, \mathrm{~A} 4$ dan $\mathrm{A} 5$ berbeda nyata antar perlakuan.

Respon tinggi tanaman terendah terdapat pada pelakuan A0 pada umur tanaman 15 dan 30 hst yaitu $3,79 \mathrm{~cm}$ dan $10,34 \mathrm{~cm}$, sedangkan tertinggi pada perlakuan A5 yaitu 5,66 cm dan 12,53 $\mathrm{cm}$. Hasil ini sejalan dengan dengan Agustina, (2006) yang menyatakan bahwa ketersediaan unsur hara akan sangat berpengaruh terhadap pertumbuhan tinggi tanaman. Keadaan demikian tidak terlepas dari banyaknya unsur hara yang dapat diserap oleh akar tanaman dari dalam tanah. Menurut (Buckman dan Brady 1969dalam Marlina dkk, 2014), untuk mendapatkan pertumbuhan yang baik, maka unsur hara harus berada dalam keadaan seimbang. Jika salah satu faktor tidak seimbang dengan unsur-unsur lain, maka dapat menghambat pertumbuhan bahkan mengurangi hasil tanaman.

$\begin{array}{crr}\text { Perakaran yang } & \text { berkembang } \\ \text { maksimal, } & \text { tanaman } & \text { mampu }\end{array}$ mengabsorbsi hara, terutama $\mathrm{N}, \mathrm{P}, \mathrm{K}$, $\mathrm{Ca}$, dan $\mathrm{Mg}$ yang disuplai oleh pupuk kotoran ayam, sehingga proses fotosintesis dan translokasi fotosintat dapat berjalan lancar. Pemupukan dengan pupuk organik seperti pupuk kandang ayam dapat memberikan pengaruh yang baik karena selain menambah unsur hara juga dapat memperbaiki sifat fisik dan aktifitas mikroorganisme tanah. tanaman menghendaki kondisi tanah sebagai media tumbuhnya memiliki sifat fisik, kimia dan biologi yang baikuntuk memperoleh hasil yang optimal. Oleh karena itu setiap upaya untuk meningkatkan hasil pertanian dengan meningkatkan produktivitas tanah harus diarahkan kepada peningkatan ketiga aspek, yaitu suplai bahan-bahan yang bersifat menambahkan unsur hara sekaligus yang dapat menahan larutnya unsur hara di dalam tanah, Sutedjo (2002) juga menyatakan bahwanitrogen merupakan unsur hara utamabagi 
Siga: Pengaruh dosis pupuk kandang ayam terhadap pertumbuhan dan produksi tanaman kacang panjang

pertumbuhan tanaman, yang padaumumnya sangat diperlukan untukpembentukan atau pertumbuhan bagian-bagianvegetatif tanaman. Denganpemberian fosfor dapat mempercepat sertamemperkuat pertumbuhan tanaman mudamenjadi tanaman dewasa pada umumnya.

\section{Pengamatan Jumlah Daun}

Secara umum hasil pengamatan terhadap jumlah daun Tanaman kacang tanah disajikan pada tabel 4.3.1 dan 4.3.2. Pengamatan jumlah daun tanaman dilakukan pada saat umur tanaman 15 dan 30 (HST).

Tabel 4.3.1Data Pengamatan Jumlah Daun (Helai) 15 hst.

\begin{tabular}{cccccccc}
\hline \multirow{2}{*}{ Perlakuan } & \multicolumn{4}{c}{ Ulangan } & Total & $\begin{array}{c}\text { Rata- } \\
\text { rata }\end{array}$ & $\begin{array}{c}\text { Simbol } \\
\text { Notasi }\end{array}$ \\
\hline A0 & 30 & 36 & 26 & 35 & 127 & 31,75 & $\mathrm{a}$ \\
$\mathbf{A 1}$ & 27 & 35 & 30 & 34 & 126 & 31,5 & $\mathrm{a}$ \\
$\mathbf{A 2}$ & 34 & 34 & 28 & 35 & 131 & 32,75 & $\mathrm{a}$ \\
$\mathbf{A 3}$ & 30 & 35 & 30 & 32 & 127 & 31,75 & $\mathrm{a}$ \\
$\mathbf{A 4}$ & 33 & 36 & 33 & 35 & 137 & 34,25 & $\mathrm{~b}$ \\
$\mathbf{A 5}$ & 31 & 36 & 28 & 34 & 129 & 32,25 & $\mathrm{a}$ \\
\hline
\end{tabular}

Rerata : 32,38 $\mathrm{KK}: 5,58$

Sumber: data primer diolah, (2018)

Tabel 4.3.2 Data Pengamatan Jumlah Daun (Helai) 30 hst.

\begin{tabular}{cccccccc}
\hline & \multicolumn{4}{c}{ Ulangan } & Total & $\begin{array}{c}\text { Rata- } \\
\text { rata }\end{array}$ & $\begin{array}{c}\text { Simbol } \\
\text { Notasi }\end{array}$ \\
\hline A0rlakuan & I & II & III & IV & & 145.13 & $\mathrm{a}$ \\
A1 & 138 & 145 & 74 & 144 & 501 & 125.5 & $\mathrm{a}$ \\
A2 & 101 & 142 & 109 & 146 & 498 & 124.50 & $\mathrm{a}$ \\
A3 & 145 & 138 & 97 & 146 & 525 & 131.13 & $\mathrm{a}$ \\
A4 & 132 & 148 & 142 & 145 & 566 & 141.38 & $\mathrm{a}$ \\
A5 & 140 & 144 & 145 & 151 & 569 & 142.25 & $\mathrm{a}$ \\
\hline
\end{tabular}

Rerata : 133,67 KK : 12,05

Sumber : data primer diolah, (2018)

Hasil pengamatan jumlah daun (helai) kacang tanah umur 15 dan 30 hst menunjukan banyaknya jumlah daun A0 31,75 dan A5 32,25. Hasil pengamatan jumlah daun dianalisis menggunakan uji ANOVA memberikan pengaruh yang nyata yaitu F-hitung lebih besar dari Ftabel. Dengan adanya pengaruh, maka dilanjutkan dengan uji lanjut Beda Nyata terkecil (BNT) 5\%. Uji BNT 5\% menunjukkan bahwa pada pengamatan jumlah daun 15 hst tidak berpengaruh nyata padaperlakuan A0, A1, A2, A3 dan A5, sedangkan perlakuan A4 berbeda dengan perlakuan lainnya. Hal ini terlihat dari jumlah daun pada perlakuan A4 34,25 (helai), paling banyak dibandingkan perlakuan lainnya. 
Pada pengamatan ke 2 jumlah daun umur 30 hst hasil uji BNT 5\% menunjukkan bahwa tidak terdapat pengaruh antar perlakuan A0,A1, A2, A3, A4 dan A5. Hal ini berarti bahwa pemberian dosis pupuk kandang pada penelitian belum memberikan pengaruh yang signifikan antar perlakuan, sehingga perlu dilakukan penambahan dosis pupuk kandang untuk meningkatkan jumlah daun kacang tanah.

Pemberian pupuk kandang (organik) ke dalam tanah sangat bermanfaatuntuk perbaikan sifat fisik tanah, sepertistruktur, porositas, aerasi tanah. Kondisi sifat fisik tanah yang lebih baikmaka terdapat manfaat bagi kacang tanah, yaitu antara lain perakaran kacang tanah dapat tumbuh dan berkembang dengan baik sehingga fungsinya sebagai organ penyerap hara dan air dari dalam tanah dapat berlangsung dengan baik.

Selain itu menurut (Budiastuti, 2000dalam Marlina dkk, 2014), bahwa cabangtanaman merupakan tempat tumbuhnya daun.Daun tanaman jumlahnya kecil pada cabangyang jumlahnya juga kecil, dan dapat didugaimplikasinya pada luas daun seluruh tanamanjuga lebih rendah. Sebagai organ tanaman yangberfungsi memanen cahaya, luas daun memegangperanan penting.Daun tanaman sebagaiorgan fotosintesis sangat berpengaruh pada hasilfotosintesis. Hasil fotosintesis yang berupa gulareduksi digunakan sebagai sumber energi untukmemelihara kehidupan tanaman, dibentuk sebagaitubuh tanaman (akar, batang, daun) sertadiakumulasikan dalam buah, biji atau organ penimbunyang lain (sink). Selanjutnya hasil fotosintesisyang tertimbun dalam bagian vegetatifsebagian diremobilisasikan ke bagian generative (polong) setelah bagian tersebut terbentuk dan tumbuh. Dengan demikian pengisian polong terjadidengan merebolisasikan fotosintat dari bagianvegetatif. Fotosintat di bagian vegetatif terekam dalam berat kering berangkasan, sedangkan fotosintat yang terakumulasi di polong tercermin dalam berat kering biji.

Selanjutnya hasil penelitian Rusnetty (2000), menunjukkan bahwa pemberian bahan organik dapat meningkatkan $\mathrm{pH}$ tanah, $\mathrm{P}$ tersedia, $\mathrm{N}$ total, KTK, Kdd dan menurunkan Al-dd, serapan $\mathrm{P}$, fraksi $\mathrm{Al}$ dan $\mathrm{Fe}$ dalam tanah, sehingga dapat meningkatkan kandungan $\mathrm{P}$ tanaman, pada akhirnya hasil tanaman juga turut meningkat. Menurut (Bagaskara ,2011dalam Marlina dkk, 2014) , unsur makroN, P, dan K mempunyai peranan masing-masing untuk tanaman diantaranya unsur nitrogen dibutuhkan untuk pertumbuhan daun dan pembentukan batang serta cabang. Khusus pada kacang-kacangan yang memiliki nodul akar, dapat memanfaatkan bakteri yang ada di udara. Unsur fosfor diperlukan bagi tanaman untuk perkembangan biji dan akar. Sementara unsur kalium berfungsi untuk membentuk bunga dan buah serta membantu tanaman melawan penyakit.

Menurut (Rosmarkam dan Yuwono, 2002dalam Marlina dkk, 2014), unsur hara nitrogen akan menaikkan produksitanaman, kadar protein dan kadar selulosa, tetapisering 
Siga: Pengaruh dosis pupuk kandang ayam terhadap pertumbuhan dan produksi tanaman kacang panjang

menurunkan kadar sukrosa, polifruktosa,dan pati. Hasil asimilasi $\mathrm{CO} 2$ diubah menjadikarbohidrat dan karbohidrat ini akan disimpandalam jaringan tanaman. Nitrogen merupakanunsur hara makro utama yang sangat pentinguntuk pertumbuhan tanaman. Nitrogen diseraptanaman dalam bentuk ion NO3- atau NH4+ daritanah. Menurut (Wijaya, 2008dalam Marlina dkk, 2014), unsur N padatanaman akan mendorong pertumbuhan organ-organyang berkaitan dengan fotosintesis yaitudaun. Tanaman yang cukup mendapat suplai $\mathrm{N}$ akan membentuk daun yang memiliki helaianlebih luas dengan kandungan klorofil yang lebihtinggi, sehingga tanaman mampu menghasilkankarbohidrat/asimilat dalam jumlah yang cukupuntuk pertumbuhan vegetatif dan produksi tanaman.

\section{Pengamatan Jumlah Polong Sampel Kacang Tanah}

Hasil pengamatan terhadap jumlah polong kacang tanah pada tanaman sampel disajikan pada tabel 4.4.1. Pengamatan jumlah polong dilakukan pada saat panen atau pada umur tanaman 90 hari setelah tanam (HST).

Tabel 4.4.1Data Pengamatan Jumlah Polong 90 hst.

\begin{tabular}{cccccccc}
\hline \multirow{2}{*}{ Perlakuan } & \multicolumn{4}{c}{ Ulangan } & Total & $\begin{array}{c}\text { Rata- } \\
\text { rata }\end{array}$ & $\begin{array}{c}\text { Simbol } \\
\text { Notasi }\end{array}$ \\
\hline A0 & 47 & 55 & 44 & 47 & 192 & 47.95 & $\mathrm{a}$ \\
A1 & 56 & 59 & 55 & 55 & 223.2 & 55.80 & $\mathrm{a}$ \\
A2 & 69 & 68 & 42 & 73 & 251 & 62.70 & $\mathrm{~b}$ \\
A3 & 61 & 64 & 50 & 62 & 237 & 59.13 & $\mathrm{a}$ \\
A4 & 71 & 69 & 56 & 72 & 268.4 & 67.10 & $\mathrm{c}$ \\
A5 & 73 & 71 & 57 & 72 & 272.9 & 68.23 & $\mathrm{~d}$ \\
\hline
\end{tabular}

Rerata : 60,15

Sumber : data primer diolah, (2018)

Pengamatan terhadap jumlah polong kacang tanah umur 90 hari setelah tanam (HST) atau umur panen, menunjukan bahwa perlakuan pupuk kandang 25 ton/ha memberikan pengaruh yang sangat nyata. Jumlah polong kacang terbanyak sampai yang paling sedikit dapat dilihat pada perlakuan A5: 68,23, A4: 67,10, A2: 62,70, A3: 59,13, A1: 55,80, dan A0: 7,95, dengan uji ANOVA berpengaruh sangat nyata yaitu F-Hitung lebih besar dari pada F-Tabel. Selanjutnya hasil uji
BNT menunjukkan bahwa perlakuan A5 memberikan pengaruh tertinggi pada pengamatan jumlah polong kacang tanah.

Hasil penelitian menunjukan bahwa pemberian pupuk kandang ayam berpengaruh sangat nyata terhadap jumlah polong tanaman kacang tanah. Semakin tinggi dosis pupuk kandang ayam maka pertumbuhan dan produksi tanaman akan semakin baik. Tetapi berbeda pada perlakuan A0 atau kontrol relatif rendah hal ini disebabkan karena 
pada perlakuan A0 tidak dilakukan pemberian pupuk sehingga kandungan unsur hara dalam tanah relatif rendah sehingga tidak memberikan pengaruh terhadap produksi polong kacang tanah.

Aplikasi takaran pupuk kandang kotoran ayam 25 ton/ha merupakan perlakuan terbaik dibanding dengan takaran pupuk kandang kotoran ayam yang lain. Hal ini disebabkan karena takaran pupuk kandang kotoran ayam sebanyak 25 ton/ha merupakan takaran yang cukup dalam memenuhi kebutuhan unsur hara yang dibutuhkan oleh tanaman kacang tanah. Dengan takaran pupuk kandang kotoran ayam yang cukup maka sifat, fisik, kimia dan biologi tanah menjadi lebih baik seperti memberi keuntungan terhadap sifat fisik tanah dan meningkatkan strukturisasi.

Pemberian pupuk kandang dapat memperbaiki struktur tanah juga menambah tersedianya unsur hara dan pertumbuhan mikroorganisme. Apabila sifat fisik tanah baik, perkembangan akar akan semakin dalam dan ekspansif sehingga penyerapan unsur hara dan air yang diperlukan tanaman juga semakin baik yang pada gilirannya akan meningkatkan produktivitas tanaman seperti pertumbuhan tanaman dan produksi tanaman meningkat (Mayadewi, 2007 dalam Marlina dkk, 2014).

Jumlah polong, jumlah ginofor gagal dan bobot kering polong secara nyata dipengaruhi oleh perlakuan pemberian pupuk kandang ayam. Dengan adanya sifat fisik tanah yang lebih baik maka terdapat dua manfaat bagi kacang tanah. Pertama, perakaran kacang tanah dapat tumbuh dan berkembang dengan baik sehingga fungsinya sebagai organ penyerap hara dan air dari dalam tanah dapat berlangsung dengan baik. Kedua, ginofor yang terbentuk setelah mencapai tanah akan dengan mudah tumbuh dan berkembang membentuk polong, karena tanah yang gembur akan memberikan keleluasaan bagi ginofor untuk berkembang secara optimal. Selain itu ditinjau dari sisi lain fungsi ginofor di dalam tanah yaitu membantu penyerapan unsur $\mathrm{Ca}$, juga dapat berlangsung dengan baik pada kondisi tanah yang gembur (Purnawanto dan Bambang, 2003dalam Marlina dkk, 2014).

Kandungan unsur hara dalam pupuk kandang yang penting untuk tanaman antara lain unsur nitrogen $(\mathrm{N})$, fosfor (P) dan kalium (K). Ketiga unsur hara inilah yang paling banyak dibutuhkan oleh tanaman. unsur makro $\mathrm{N}$, $\mathrm{P}$, dan $\mathrm{K}$ mempunyai peranan masing-masing untuk tanaman diantaranya unsur nitrogen dibutuhkan untuk pertumbuhan daun dan pembentukan batang serta cabang. Khusus pada kacang-kacangan yang memiliki nodul akar, dapat memanfaatkan bakteri yang ada di udara. Unsur fosfor diperlukan bagi tanaman untuk perkembangan biji dan akar. Sementara unsur kalium berfungsi untuk membentuk bunga dan buah serta membantu tanaman melawan penyakit(Bagaskara, 2011 dalam Marlina dkk, 2014).

Tanaman membutuhkan unsur hara yang cukup dan berimbang. Apabila unsur hara diberikan dalam dosis yang berlebihan atau dosis rendah akan menyebabkan berat segar tanaman akan 
Siga: Pengaruh dosis pupuk kandang ayam terhadap pertumbuhan dan produksi tanaman kacang panjang

menurun. Kekurangan atau kelebihan unsur hara yang diberikan pada tanaman mengakibatkan proses fotosintesis tidak berjalan efektif dan fotosintat yang dihasilkan berkurang, menyebabkan jumlah fotosintat yang ditranslokasikan ke polong menjadi berkurang. Ketersediaan unsur hara dalam tanah secara berimbang memungkinkan pertumbuhan dan produksi tanaman berlangsung dengan baik(Gardner dkk, 2018 dalam Marlina dkk, 2014).

\section{Pengamatan Berat Basah Polong Sampel Kacang Tanah}

Hasil pengamatan terhadap berat basah polong kacang tanah pada tanaman sampel setelah dianalisis menggunakan uji $\mathrm{F}$, disajikan pada tabel 4.5.1 dibawah ini.

Tabel 4.5.1. Data Pengamatan Berat Basah (kg) Polong Tanaman Sampel 90 hst.

\begin{tabular}{|c|c|c|c|c|c|c|c|}
\hline \multirow{2}{*}{ Perlakuan } & \multicolumn{4}{|c|}{ Ulangan } & \multirow{2}{*}{ Total } & \multirow{2}{*}{$\begin{array}{c}\text { Rata- } \\
\text { rata }\end{array}$} & \multirow{2}{*}{$\begin{array}{l}\text { Simbol } \\
\text { Notasi }\end{array}$} \\
\hline & I & II & III & IV & & & \\
\hline A0 & 1.00 & 0.80 & 0.90 & 0.80 & 4 & 0.88 & $\mathrm{a}$ \\
\hline A1 & 1.50 & 1.50 & 1.20 & 1.00 & 5.2 & 1.30 & $\mathrm{~b}$ \\
\hline A2 & 1.80 & 1.80 & 1.00 & 1.00 & 6 & 1.40 & $\mathrm{c}$ \\
\hline A3 & 2.00 & 1.40 & 1.00 & 1.50 & 6 & 1.48 & $\mathrm{~d}$ \\
\hline A4 & 2.00 & 2.00 & 1.30 & 1.80 & 7.1 & 1.78 & e \\
\hline A5 & 2.00 & 2.00 & 1.30 & 2.00 & 7.3 & 1.83 & $\mathrm{f}$ \\
\hline
\end{tabular}

Rerata : 8,65

Sumber : data primer diolah, (2018)

Hasil pengamatan bobot atau berat basah tanaman sampel pada umur 90 hari setelah (HST) atau masa panen, terdapat perbedaan yang sangat nyata diantara masing-masing perlakuan dimana nilai uji F-hitung lebih besar dibandingkan dengan F-tabel. Hasil penelitian menunjukan berat basah polong tertinggi $1,83 \mathrm{~kg}$ pada perlakuan A5 dan yang terendah $0,88 \mathrm{~kg}$ pada perlakuan A0 (kontrol). Hal ini berarti bahwa semakin tinggi dosis pupuk kandang ayam dapat meningkatkanbobot polong per tanaman. Mikroba yangterkandung dalam pupuk kandang ayam dapatmerubah bentuk ikatan kompleks organik dananorgaik yang tidak dapat dimanfaatkan olehtanaman menjadi bentuk senyawa organikdan anorganik sederhana yang dapat diserapoleh tanaman. Hal ini terjadi karena dengan peningkatan takaran pupuk berarti ketersediaan unsur hara yang dimanfaatkan oleh tanaman lebih banyak, sesuai dengan kondisi pertumbuhan tanaman kacang tanah yang menghendaki tanah subur, sehingga tanaman dapat memanfaatkan unsur hara dalam tanah untuk pertumbuhan dan poduksi tanaman.

Menurut pendapat Sugito dkk(1995), menyatakan bahwa penggunaan pupuk organik memberikan beberapa manfaat seperti mensuplai hara makro dan mikro, meningkatkan kandungan bahan organik tanah sehingga memperbaiki kemampuan tanah menahan air serta menambah 
porositas tanah dan meningkatkan kegiatan jasad renik didalam tanah. Dengan demikian penambahan bahan organik dapat menggemburkan tanah. Pada kondisi tanah yang gembur tersebut dibutuhkan untuk mempermudah ginofor menembus tanah. Selanjutnya(Wijaya, 2008dalamMarlina dkk, 2014), menyatakan bahwa pemberian bahan organik dalam menyediakan unsur nitrogen, kalium, kalsium, dan ketersediaan unsur fosfor yang mudah larut dalam tanah cukup diperlukan tanaman untuk perkembangan polong tanaman kacang tanah.

\section{KESIMPULAN}

Berdasarkan isi hasil analisis data pembahasan dapat diambil kesimpulan:

1. Pemberian pupuk kandang ayam berpengaruh nyata terhadap tinggi tanaman danjumlah daun pada umur tanaman kacang tanah 15 dan 30 hari setelah tanam,sertaberpengaruh sangat nyata terhadap jumlah polong dan berat basah polong kacang tanah umur 90 hari setelah tanam.

2. Dosis pupuk kandang ayam 25 ton/ha dalam penelitian ini merupakan perlakuan dosis pupuk terbaik untuk memberikan pertumbuhan dan produksi tertinggi tanaman kacang tanah hypoma 1.

\section{UCAPAN TERIMA KASIH}

Pada kesempatan ini penulis ingin mengucapkan terima kasih kepada semua pihak yang telah membantu dengan caranya masing-masing dalam melengkapi tulisan ini.

\section{DAFTAR PUSTAKA}

Adisarwanto, T. 2000. Meningkatkan Produksi Kacang Tanah di Lahan Sawah dan Lahan Kering. Penebar Swadaya, Jakarta.

Agustina A. 2006. Nutrisi Tanaman. Rineka Cipta Jakarta.

Anonim. 2011. Pupuk Organik, Pupuk Hayati, dan Pembenah Tanah. Tersedia pada:http://perundangan.perta nian.go.id/admin/file/Perment an-70 11.pdf. Diakses 28 April 2018

Badan Litbang Pertanian. 2012. Deskripsi Varietas Unggul Baru Kacang-kacangan dan Umbi-umbian. Kementan

Bukman, H, O. dan Brady, 1982. Dasar ilmu tanah. Bhatara karya, Jakarta.

Depertemen kesehatan RI. 1996. Kandungan Gizi Kacang Tanah Per $100 \mathrm{~g}$. Direktorat Gizi, Departemen Kesehatan RI.

Dinas Pertanian Kabupaten Sikka. 2018. Data produksi tanaman hortikultura dari tahun 20152017

Endriani, Yunus, dan Zurhalena. 2002. Meningkatkan efisien pupuk $P$ 
Siga: Pengaruh dosis pupuk kandang ayam terhadap pertumbuhan dan produksi tanaman kacang panjang

melalui pemberian pupuk kandang pada tanah masam. $\mathbf{J}$ Stigma. 7(4):445-448

Goenadi, D. H., R. Saraswati, N. N. Nganro, dan J. A. S. Adiningsih. 1995. Nutrient solu-bilizingand aggregatestabilizing microbes isolated from selected humic tropical soil. Manara Perkebunan 63 (2):60-66

Golombek, S. D and C. Johansen. 1997. Effect of soil temperature on vegetative and reproduntive growth and development in trhree spanish genotypes of peanut (arachis hypogea L.). Peanut Science (24): 67-72

Hartati,Winarno, Novarizki, 2008.Status unsur hara ca, mg, dan s sebagai dasar pemupukan tanaman kacang tanah (arachis hypogaea L.), Surakarta

Hartatik, W. Dan L. R. Widowati. 2010. Pupuk Kandang. http:// www.balittanah. litbang. deptan.go.id. Diakses 20 Apri 2018

Hartoni. 2014. Pengolahan Lahan Tanah Ketela Pohon Singkong. Serial online (http://agromaret.com/a rtikel/621/pengolahan_lahan_t anah_ketela_pohon_singkong) . Diakses 18April 2018

HudaG. N. 2007. Peranan Mikroba Pelarut Fosfat Terhadap
Pertumbuhan Tanaman.

Diakses tanggal 10 Maret 2018.

Jazilah, S., Sunarto dan N. Farid. 2007. Respon Tiga Varietas Bawang Merah Terhadap Dua Macam Pupuk Kandang dan Empat Dosis Pupuk Anorganik. J. Agrin 11 (1):43-51.

Kasno, A. 2005. Profil dan Perkembangan Teknik Produksi Kacang Tanah di Indonesia.http:www.puslittan. bogor.net/addmin/downloads/ Astanto.pdf. Diakses 5 April 2018.

Lingga. 1992. PetunjukPenggunaan Pupuk. Penebar Swadaya. Jakarta. 180 hlm

Manurung, M. 2016. Pengaruh DosisPupuk kandang Terhadap PertumbuhanDan Hasil kacang Tanah (arachyshipogea L.). Jurnal Ilmiah ResearchSains, 2(3).

Marlina, N., Aminah, R. I. S.,Rosmiah, R., \& Setel, L. R. 2014. Aplikasi Pupuk Kandang Kotoran Ayam Pada Tanaman Kacang Tanah (arachis hypogea L.)Biosaintifika,7 (2). https://doi.org/10.15294/biosai ntifika. v7i2.3957

Marzuki, R. 2007. Bertanam Kacang Tanah. Jakarta: Penebar Swadaya. 
Musnamar, E. I. 2003. Pupuk Organik.

Novizan. 2002. Petunjuk Pemupukan Yang Efektif. Jakarta: Agro Media Pustaka.

Pardono. 2009. Pengaruh Pupuk Organik Air Kencing Sapi dan Pupuk Kandang terhadap Pertumbuhan dan Hasil Kacang Panjang (Vignasinensis L.)

Pudjiatmoko. 2008.Budidaya Tomat. Jurnal Atani Tokyo. http://www.atanitokyo. blogspot.com

Prihatman, k. 2000. Kacang Tanah (arachis hypogaea L.). Kantor Deputi Menegristek Bidang Pendayagunaan dan Pemasyarakatan Ilmu Pengetahuan dan Teknologi. Jakarta.

Roidah, I. S. 2013.Manfaat Penggunaan Pupuk Organik untuk Kesuburan Tanah, Jurnal Universitas Tulungagung Bonorowo 1(1): 30-42

Ross, B. B. 2007. Peanut Irrigation. http://pubs.ext. vt.edu. Diakses 15 April 2018

Rukmana. 2007. Budidaya Kacang Tanah. Jakarta: Penebar Swadaya

Rusnetty. 2000. Beberapa Sifat Kimia Erapan P, Fraksionasi Al dan
Penebar Swadaya. Jakarta. Fe Tanah, Serapan Hara, serta Hasil Jagung Akibat Pemberian Bahan Organik dan Fosfat Alam pada Ultisols Sitiung. [Disertasi]. Bandung: Universitas Padjadjaran

Scholes,M.C., Swift, O.W., Heal, P.A. Sanchez, JSI., Ingram and R. Dudal. 1994. Soil Fertility research in response to demand for sustainability. In The biological managemant of tropical soil fertility (Eds Woomer, Pl. and Swift, MJ.) John Wiley \& Sons. New York

Setiawan, A. I. 2002. Manfaat Kotoran Ternak. Penebar Swadaya. Jakarta

Sudjadi, M dan Y. Supriati. 2001. Perbaikan Teknologi Produksi Kacang Tanah di Indonesia. Balai Penelitian Bioteknologi Tanaman Pangan,Bogor. Buletin AgroBio 4(2): 62-68

Suntoro W. Atmojo. 2003. Pidato Pengukuhan Guru Besar Ilmu Kesuburan Tanah. Fakultas Pertanian, Surakarta

Suprapto. 1993. Bertanam Kacang Tanah. PT. Penebar Swadaya.Jakarta

Sutedjo M. M. 2002. Pupuk dan Cara Pemupukan. Rineka Cipta. Jakarta. 110 hlm. 
Siga: Pengaruh dosis pupuk kandang ayam terhadap pertumbuhan dan produksi tanaman kacang panjang

Sutanto, R. 2002. Perbedaan Antara Pupuk Anorganik dan Pupuk Organik.

http://repository.ipb.ac.id/bitst ream/handle/12345689/52826/ BAB\%20I\%20Pendahuluan.p df ?sequence $=3$. Diakses 12 April 2018

Tian G., L. Brussard, B. T., Kang and M.J. Swift. 1997. Soil Fauna Mediated Decomposition of Plant Residues Under Contreined Environmental and Residue Quality Condition. In Nature Plant Litter Quality and Decomposition, Department of Biological Sciences. (Eds
Cadisch, G. and Giller, K.E.), pp. 125- 134. University of London, UK

Tim bina karya tani. 2009. Kacang tanah. Bandung. Yrama Widia.

Tjahjo Purtomo, Siti Mujanah \&Tiurma Wiliana Susanti P. 2014. Pengaruh Penggunaan Pupuk Organik Hayati Herhadap Sifat Kimia Tanah Pertanian.UNTAG, Surabaya

Yitnosumarto. 1993. Perancangan Percobaan Analisis Dan Interpretasinya. Jakarta, PT. Gramedia Pustaka Utama. 